\title{
Carbon pricing, technology transition, and skill-based development
}

\section{Journal Article}

\section{Author(s):}

Borissov, Kirill; Brausmann, Alexandra; Bretschger, Lucas

Publication date:

2019-09

Permanent link:

https://doi.org/10.3929/ethz-b-000348926

\section{Rights / license:}

Creative Commons Attribution-NonCommercial-NoDerivatives 4.0 International

\section{Originally published in:}

European Economic Review 118, https://doi.org/10.1016/j.euroecorev.2019.05.011 


\title{
Carbon pricing, technology transition,and skill-based development
}

\author{
Kirill Borissov ${ }^{\mathrm{a}, \mathrm{b}}$, Alexandra Brausmann ${ }^{\mathrm{c}}$, Lucas Bretschger ${ }^{\mathrm{c}, *}$ \\ a European University at St. Petersburg, 6/1A Gagarinskaya Street, St. Petersburg 191187 Russia \\ ${ }^{\mathrm{b}}$ Institute for Regional Economic Studies, Russian Academy of Sciences, 38 Serpukhovskaya Street, St. Petersburg 190013 Russia \\ ${ }^{\mathrm{c}}$ CER-ETH Center of Economic Research at ETH Zurich, CH-8092 Zurich ZUE F7, Switzerland
}

\section{A R T I C L E I N F O}

\section{Article history:}

Received 19 January 2018

Accepted 24 May 2019

Available online 31 May 2019

\section{JEL classification:}

Q43

047

Q56

O41

Keywords:

Carbon pricing

Education

Clean and dirty technologies

Temporary policies

\begin{abstract}
A B S T R A C T
We analyze the impact of carbon prices on human capital accumulation, sectoral change, and economic growth. In our framework output is produced with dirty and/or clean technologies using skilled and unskilled labor as inputs. Carbon policy affects technology selection which transmits incentives for human capital formation. We show that a temporary policy may be sufficient for a transition to a clean economy and that such a policy also stimulates economic growth. Moreover, in the presence of inter-country knowledge spillovers, a carbon policy in the North helps human capital formation in the South and induces South's transition to the clean steady state.
\end{abstract}

(C) 2019 The Authors. Published by Elsevier B.V. This is an open access article under the CC BY-NC-ND license. (http://creativecommons.org/licenses/by-nc-nd/4.0/)

\section{Introduction}

\subsection{Environment and technology}

Economic costs and the restriction of feasible technology tend to dominate public perception of environmental policies. Improvements in the natural environment as well as economic benefits, such as induced accumulation of human and knowledge capital, appear less imminent because they are distributed over a longer time horizon. In the case of climate policy, environmental benefits are spread globally which weakens policy efforts of individual countries and gives strong incentives for free-riding. Given these challenging conditions it becomes a strong requirement that policy instruments be carefully selected and fully assessed in all dimensions. Economists mostly agree that global carbon pricing allows reaching the internationally accepted temperature targets at minimal cost (Gollier and Tirole, 2015). Also, a uniform carbon price may act as a focal point facilitating international climate negotiations (Weitzman, 2014; Cramton et al., 2017). To address the concerns of undesirable distributional consequences, possible time delays, and different national circumstances a recent report on carbon pricing (High-Level Commission, p. 17 ff.) suggests that lower-income countries should be allowed to choose less stringent

\footnotetext{
* Corresponding author.

E-mail addresses: kirill@eu.spb.ru (K. Borissov), abrausmann@ethz.ch (A. Brausmann), lbretschger@ethz.ch (L. Bretschger).
} 
policy measures and that pricing should be supplemented by other policies and a suitable redistribution of tax revenues. ${ }^{1}$ Finally, putting a price on carbon may guide economic development in a favorable way. The crucial dynamic effects of environmental policies were stressed in earlier contributions (Bovenberg and Smulders, 1995; Bovenberg and de Mooij, 1997) but have received much less attention in the current climate policy literature. Nevertheless, the report of the commission on carbon pricing explains the role of education and skilled labor for the transition to green growth. ${ }^{2}$ It explains that production using clean technologies is human capital intensive so that education decisions become closely interlinked with the energy transition. In the same vein, an earlier report found that shortages of skilled labor may constrain the decarbonization process of an economy (Bank, 2012). In a broad empirical study, (Vona et al., 2018) find that "green" skills are closely related to the design, production, management and monitoring of technology and conclude that education emerges as a critical ingredient in the policy mix to promote sustainable economic growth. ${ }^{3}$ (OECD, 2017), p. 16) states that the "transition to a low-carbon, resource-efficient and green economy can only be made by developing the right skills, knowledge and competencies." This evidence suggests that clean sectors tend to be skill-intensive in production. As a consequence, carbon pricing - by its impact on human capital accumulation - may not only be the cornerstone of climate policy but may also act as a development policy, fostering technology switches and education of the labor force. This is where the present paper aims to make a contribution.

We study the impact of carbon prices on the selection of competing technologies and on human capital accumulation driving long-run economic development. The considered economy uses skilled and unskilled labor for production and has a dirty and a clean technology available to combine the inputs. The education process, allowing individuals to acquire skills, constitutes the central building block of our model. The basic mechanism of this building block relies on two empirical regularities which are well documented and widely used in the literature, namely the positive effect of human capital accumulation on total factor productivity (TFP) growth and positive intergenerational spillovers. The central impact of education on welfare and growth has been highlighted in the seminal contribution of Lucas (1988). Glomm and Ravikumar (1992) introduce human capital transfers between generations, assuming that each agent's stock of human capital depends on the parent's stock of human capital and the quality of schools. To explain persistent inequalities in growing economies, De la and Doepke (2003) posit intergenerational human capital spillovers in the sense that poor parents invest little in education of their children while wealthy families give higher priority to human capital formation. In our model we incorporate the positive spillovers of human capital between generations.

The setup provides a microeconomic foundation for the supply of skilled labor which adds an important element to technology-driven growth models. We show that introducing a carbon tax affects the technology choice which in turn transmits incentives for human capital accumulation. Specifically, an appropriate tax induces a transition to a cleaner sectoral mix possibly up to a fully clean economy while at the same time raising the skill level of the population. We find that a temporary policy may be sufficient to appropriately address environmental problems which is an attractive feature for policy making in the presence of potentially strong opposition. Once the transition to the fully clean economy has been completed, the carbon tax may be totally eliminated. Thus, a transition to a clean steady-state equilibrium is compatible with a declining tax over time.

Another dimension of knowledge spillovers concerns technology, know-how and human capital transfer from the advanced to the developing economies, the so-called North-South spillover. We show that introduction of a carbon tax in the North promotes development in the South by boosting its human capital accumulation and growth in TFP, even without the South having to implement any carbon policy itself.

\subsection{Contribution to the literature}

By distinguishing between clean and dirty production and by deriving long-lasting effects of temporary policies our paper is close to Acemoglu et al. (2012). While their contribution features directed technical change ${ }^{4}$ we rely on human capital accumulation as an engine of transition and growth. We endogenously derive the skill level in the economy and focus on a single final output (think of heating or transportation) which can be produced with dirty and/or clean technology (e.g. using fossil energies or renewables). The paper is linked to the literature deriving sectoral reallocation and growth effects induced by environmental policy; a survey is provided by Ricci (2007). ${ }^{5}$ Bovenberg and de Mooij (1997) suggested a "double

\footnotetext{
1 Borissov and Bretschger (2018) provide a theoretical foundation for specific optimal country policies when countries differ in terms of income. Equity consideration as a guideline for feasible climate policies are presented in Bretschger (2017).

2 The report concludes that the "restructuring process can be done quicker and more efficiently if it is supported by education, migration, and trade policies that accelerate technology transfers and innovation. Decarbonization poses the usual challenges for policy makers trying to facilitate the restructuring and reduce the labor market adjustment costs, including those derived from a changing skills mix" (Prices, 2017, p. 49).

3 Consoli et al. (2016) find for the United States that green jobs use relatively more intensively high-level cognitive and interpersonal skills and exhibit higher levels of human capital. (C. et al., 2010), p.17) writes that "as the green economy grows, there will be an increased demand for highly skilled and qualified labor capable of undertaking the increasing technological and innovation demands." Examining the experiences of developed and developing countries, Strietska-Ilina et al. (2012) conclude that the shift to a green economy is increasing the pace of change in skill needs.

4 A related earlier theoretical contribution is Smulders and de Nooij (2003) and Aghion et al. (2016) show empirically that firms innovate more in clean technologies when they face higher tax-inclusive fuel prices.

5 The conditions under which environmental regulation fosters innovation and competitiveness are surveyed by Ambec et al. (2013).
} 
dividend" of environmental policy yielding both positive environmental and growth impacts. ${ }^{6}$ While most of the theoretical models on environment and growth use physical or knowledge capital (e.g. Michel and Rotillon, 1995) the contributions focusing on education are less numerous. Human capital as an engine of growth was incorporated into growth theory by Uzawa (1965). Its role was later emphasized by Lucas (1988). In the intergenerational perspective, human capital has been identified as a major cause of persistent inequalities, see Glomm and Ravikumar (1992) and De la and Doepke (2003). Recent years have witnessed a remarkable revival of interest in the role of human capital as a vital component of the process of economic growth (see e.g., Jones, 2014; Lucas, 2015; Manuelli and Seshadri, 2014). An early adaptation of the UzawaLucas growth model to environmental economics is provided by Hettich (1998) who derives a positive growth effect of environmental taxation which is a consequence of inputs being reallocated from (dirty) production to (clean) education. The effects of pollution and environmental policy on human capital accumulation are also analyzed in Bosi and Ragot (2013) who derive a positive relationship between pollution and working time (which competes with time for education). Adding to their contribution we introduce an explicit education decision for the acquisition of skills and provide closed-form solutions for all the cases based on different initial conditions. Empirical evidence on the link between the environment and human capital accumulation is provided by Sapci and Shogren (2018).

In the transition to a clean economy, human capital plays an important part not only for environmental policy but also when such a policy is lacking. ${ }^{7}$ A series of recent contributions highlights the significant positive relationship between the state of the environment and individual well-being, including health but also labor productivity and human capital (Zivin and Neidell, 2012; Zivin and Neidell, 2013; Zivin et al., 2016). These authors conclude that, given the importance of health and human capital as drivers of economic growth, environmental conditions become an important factor of production and long-run development. The case of pollution- induced health shocks and their impact on growth has been analyzed in a theoretical paper by Bretschger and Vinogradova (2017).

The present paper is organized as follows. Section 2 presents our baseline model. Section 3 describes short-run equilibria and their dependence on the carbon tax. Section 4 is devoted to the dynamics of the model and the impact of the carbon tax on the long-run behavior of the economy. Section 5 presents an endogenous-growth version of the model and a North-South set-up. Section 6 concludes.

\section{Baseline model}

Two key building blocks of our model are agents, who make decisions about acquisition of human capital, and the production sector, which uses two types of technology (dirty and clean) to produce a homogeneous consumption good. We consider an infinite-horizon discrete-time economy where all agents are initially identical and possess identical preferences. The agents' decisions with respect to acquisition of education and skills translate into the aggregate human capital level in the economy, which in turn determines the ease at which human capital can be acquired by the next generation. Since the clean and the dirty production processes are assumed to differ in skill intensity, the aggregate human capital level determines which technology prevails from the outset and how a transition from the dirty to a clean steady state can be accomplished via a carbon policy and the associated process of human capital accumulation. Let us therefore turn first to the microfoundations of the latter.

\subsection{The agents and labor supply}

Our paper presents a model of successive generations. Each agent lives for one period. At each period $t$ there is a continuum of agents with measure normalized to 1 . Each agent is initially identical and has a choice between becoming skilled or unskilled worker. Acquiring education comes at the expense of labor income. Individual $i$ living in period $t$ spends $e_{t}$ of her time on acquiring advanced education, while the remaining time, $1-e_{t}$, is spent on work. Each individual in the labor market can supply either one unit of unskilled labor or some amount of human capital. If the individual decides to be unskilled, she sets $e_{t}=0$ and spends all her time working. If she decides to be a human capital supplier, she must spend some time on higher education. Her individual human capital $\zeta_{t}$ depends on the aggregate (effective) human capital level at time $t-1, H_{t-1}$, and the time she spends on education, $e_{t}$ :

$$
\zeta_{t}=\mu\left(H_{t-1}\right) \varphi\left(e_{t}\right)
$$

where $\varphi:[0,1] \rightarrow \mathbb{R}_{+}$and $\mu: \mathbb{R}_{+} \rightarrow \mathbb{R}_{+}$are increasing continuous strictly concave functions such that $\varphi(0)=0$ and $\mu(0)>0$. The effective amount of human capital she supplies on the labor market is

$$
h_{t}:=\left(1-e_{t}\right) \zeta_{t} .
$$

The function $\mu(\cdot)$ captures the idea that the aggregate human capital level matters - people living in an educated society find it easier to acquire skills - though at a diminishing rate. It adopts the positive human capital spillovers in

\footnotetext{
${ }^{6}$ An empirical study for OECD countries finds evidence for positive growth effects of increasing energy prices, see (Bretschger, 2015).

7 The (negative) impact of temperature on economic growth is empirically tested by Dell et al. (2012).
} 
Lucas (1988) and the intergenerational persistence of human capital in Glomm and Ravikumar (1992) and De la and Doepke (2003). Suppose our individual decides to be educated. Then she first maximizes the effective amount of her human capital by solving the following problem:

$$
\max _{e \in[0,1]} \mu\left(H_{t-1}\right) \varphi(e)(1-e) \text {. }
$$

Since $\varphi(\cdot)$ is a concave function, this problem has a unique solution $\hat{e}$. Therefore, the effective amount of her human capital is

$$
h_{t}=\psi\left(H_{t-1}\right)
$$

where

$$
\psi(H):=\mu(H) \varphi(\hat{e})(1-\hat{e})
$$

and $\psi(\cdot)$ is a continuous, concave and increasing function such that $\psi(0)>0$.

To decide whether to be skilled or unskilled, the individual compares the wages she earns in the two cases. If being skilled gives her a higher wage income than being unskilled, she decides to be skilled. If the wage of an unskilled worker is higher than the wage she would make as a skilled worker, she decides to be unskilled. Formally, let $w_{t}^{H}$ be the prevailing skilled workers' wage per unit of human capital at time $t$ and $w_{t}^{L}$ be the prevailing wage for unskilled workers. Individual $i$ decides to be educated if $w_{t}^{H} h_{t}>w_{t}^{L}$. If $w_{t}^{H} h_{t}<w_{t}^{L}$, then she decides not to be educated and to supply one unit of unskilled labor in the labor market. If $w_{t}^{H} h_{t}=w_{t}^{L}$, she is indifferent between being educated and uneducated. This condition determines the individual supply of human capital. ${ }^{8}$ The demand for skilled workers is determined on the production side, which we introduce in the next subsection. For now we note that, since the population is normalized to 1 , if $L_{t}$ is the number of unskilled agents in period $t$ and $h_{t}$ the effective human capital of a skilled agent, then the total supply of effective human capital is

$$
H_{t}=\left(1-L_{t}\right) h_{t} .
$$

Our approach simplifies the modeling of education by disregarding the time lag between individual investment in human capital and the results of the investment. As time lags may alter transitional dynamics but not the nature of long-run steady state we argue that our model results are robust against changes of the timing. Also, we do not have spillover effects at the individual level but focus on the positive effects of a higher human capital stock on the subsequent generation. ${ }^{9}$

\subsection{Production and labor demand}

The economy produces one consumption good using two technologies, clean technology labeled by $c$ and dirty technology labeled by $d$. The output $Y_{t}^{j}$ in sector $j=c, d$ at time $t$ is determined by the production function $F^{j}: \mathbb{R}_{+}^{2} \rightarrow \mathbb{R}_{+}$:

$$
Y_{t}^{j}=F^{j}\left(H_{t}^{j}, L_{t}^{j}\right)
$$

where $H_{t}^{j}$ and $L_{t}^{j}$ are the inputs of effective human capital and unskilled labor in technology $j=c, d$. The total output (GDP) is the sum of the outputs in the two sectors $\left(Y_{t}^{c}+Y_{t}^{d}\right)$. The two sectors are perfectly competitive and human capital and unskilled labor are fully mobile between them. In Section 5 we also consider an endogenous-growth version of our model in which the growth rate of TFP at each time depends positively on the amount of human capital accumulated by the economy up to that time.

The production functions $F^{j}(H, L), j=c, d$, are continuous, twice continuously differentiable on $\mathbb{R}_{++}$, strictly concave in each input, exhibit constant returns to scale and satisfy the Inada conditions.

Let us define by $\eta=H / L$ the ratio of human capital to unskilled labor. Based on the evidence presented in the introductory section we shall make the following assumption concerning the production technology:

Assumption 1. The clean sector $c$ is human-capital intensive: for any value of the input ratio $\eta$ the marginal productivity of human capital relative to raw labor in sector $c$ is higher than that in the dirty sector $d$.

For the rest of the analysis it is useful to define the ratio of the marginal productivity of unskilled to skilled labor in sector $j=c, d$ :

$$
\xi^{j}(\eta):=\left.\frac{F_{L}^{j}(H, L)}{F_{H}^{j}(H, L)}\right|_{H=\eta, L=1}\left(=\frac{F_{L}^{j}(H, L)}{F_{H}^{j}(H, L)} \forall(H, L) \in \mathbb{R}_{++}^{2} \mid \frac{H}{L}=\eta\right) .
$$

\footnotetext{
8 We assume that all agents are identical in their ability to learn. Therefore in equilibrium the wages of unskilled and skilled agents are equal. If we assumed heterogeneity in ability to learn or introduced an intergenerational externality within dynasties, the wage of unskilled workers would be equal to the wage of the least talented skill worker.

${ }^{9}$ It would add complexity but not change the general model conclusions when building an overlapping-generations version of our model where agents invest in human capital when young and work when old and to assume some kind of within families intergenerational externalities. Under such an assumption today's cost of individual human capital acquisition would be dependent not only on yesterday's aggregate level of human capital, but also on the level of human capital of her dynasty. We do not see a fundamental change or any "value added" of the more complicated model structure and thus prefer to stick with the simpler version as presented here.
} 
One may think of $1 / \xi^{j}(\eta)$ as the inverse relative demand function for skilled labor in sector $j$. Given our Assumption 1 , we have:

$$
\xi^{c}(\eta)<\xi^{d}(\eta) \forall \eta>0 .
$$

Since $F^{j}(H, L), j=c, d$, are twice continuously differentiable on $\mathbb{R}_{++}$and strictly concave in each input, the functions $\xi^{j}(\cdot)$ are differentiable and increasing. By the Inada condition, for $j=c, d$, we have

$$
\xi^{j}(\eta) \underset{\eta \rightarrow 0}{\longrightarrow} 0, \xi^{j}(\eta) \underset{\eta \rightarrow \infty}{\longrightarrow} \infty .
$$

It follows that the functions $\xi^{j}(\cdot), j=c, d$, are invertible in $\mathbb{R}_{++}$.

We assume that the dirty sector is not absolutely inferior to the clean sector in terms of output, formally written as

Assumption 2. There exists $(H, L)$ such that $F^{d}(H, L)>F^{c}(H, L)$.

If the production functions are Cobb-Douglas,

$$
F^{j}(H, L)=a^{j} H^{\alpha^{j}} L^{1-\alpha^{j}}, j=c, d,
$$

then Assumption 2 holds unambiguously while Assumption 1 holds true if $\alpha^{c}>\alpha^{d}$, because

$$
\xi^{j}(\eta)=\frac{1-\alpha^{j}}{\alpha^{j}} \eta, j=c, d
$$

\section{Short-run equilibrium}

We turn next to the characterization of the short-run equilibrium in our economy assuming that a carbon tax $\tau \geq 0$ is imposed on the dirty output. The collected tax is redistributed in a lump sum way.

\subsection{Equilibrium conditions}

In a short-run equilibrium, profits in clean and dirty sectors are maximized (and equal to zero due to our assumption of competitiveness), the human capital and the unskilled labor are optimally supplied, the wage rates are equalized, and labor markets for skilled and unskilled labor clear. In formal terms we state

Definition 1. Suppose that at some point in time the effective human capital of a skilled agent is equal to $h>0$. A tuple $\left\{H^{*}, L^{*}, H^{c *}, L^{C *}, H^{d *}, L^{d *}, w^{H *}, w^{L *}\right\}$ is called a short-run $\tau$-h-equilibrium if the following conditions are satisfied:

1) $F^{c}\left(H^{c *}, L^{c *}\right)-\left[w^{H *} H^{c *}+w^{L *} L^{c *}\right]=\max _{H, L}\left\{F^{c}(H, L)-\left[w^{H *} H+w^{L *} L\right]\right\}=0$,

2) $(1-\tau) F^{d}\left(H^{d *}, L^{d *}\right)-\left[w^{H *} H^{d *}+w^{L *} L^{d *}\right]=\max _{H, L}\left\{(1-\tau) F^{d}(H, L)-\left[w^{H *} H+w^{L *} L\right]\right\}=0$,

3) $w^{L *} / w^{H *}=h$,

4) $H^{c *}+H^{d *}=H, L^{c *}+L^{d *}=L^{*}$,

5) $H^{*}=\left(1-L^{*}\right) h$ (or, equivalently, $\left.H^{*} / h+L^{*}=1\right)$.

The equilibrium is called dirty if $H^{c *}=0, L^{c *}=0, H^{d *}>0$ and $L^{d *}>0$, and clean if $H^{c *}>0, L^{c *}>0, H^{d *}=0$ and $L^{d *}=0$.

These conditions have the standard interpretation. Conditions (1) and (2) are the profit maximization conditions in the clean and the dirty sector, respectively. Condition (3) describes the labor market equilibrium. Condition (4) is the full employment condition, while (5) determines the aggregate amount of human capital. Note that in equilibrium, the shares of both skilled and unskilled individuals in the population are positive. Scenarios where all agents are skilled or all agents are unskilled are not feasible. Indeed, if all agents decided to be unskilled, then the wage paid to skilled workers would be so high compared with the wage of unskilled workers that all unskilled agents would have incentives to become skilled. Conversely, if all agents decided to be skilled, then the wage rate of unskilled workers would be so high that each skilled agents would prefer to be unskilled.

\subsection{Preliminary steps}

To characterize short-run $\tau$-h-equilibria, we first need to determine the pattern of diversification in our economy. We write $\mathcal{F}(\tau, H, L)$ for the maximized after-tax GDP function which is given by

$$
\mathcal{F}(\tau, H, L):=\max _{H^{c}, L^{c}, H^{d}, L^{d}}\left\{F^{c}\left(H^{c}, L^{c}\right)+(1-\tau) F^{d}\left(H^{d}, L^{d}\right) \mid H^{c}+H^{d} \leq H, L^{c}+L^{d} \leq L\right\} .
$$

The function $\mathcal{F}(\tau, H, L)$ is differentiable in $(H, L)$ on $\mathbb{R}_{++}^{2}$ and concave (but is not strictly concave in each input) and exhibits constant returns to scale. When $\left(H^{c *}, L^{c *}, H^{d *}, L^{d *}\right)$ is a solution to the maximization problem in $(4)$ at $H=H^{*}$ and $L=L^{*}$ we can state

$$
F^{c}\left(H^{c *}, L^{c *}\right)+(1-\tau) F^{d}\left(H^{d *}, L^{d *}\right)=\mathcal{F}\left(\tau, H^{*}, L^{*}\right)
$$


while the input prices are given by

$$
w^{H *}=\mathcal{F}_{H}\left(\tau, H^{*}, L^{*}\right), w^{L *}=\mathcal{F}_{L}\left(\tau, H^{*}, L^{*}\right) .
$$

Now, for a given $\tau$, we denote the ratio of relative demands for unskilled labor and human capital in the economy by $\xi(\tau, \eta)$ :

$$
\xi(\tau, \eta):=\left.\frac{\mathcal{F}_{L}(\tau, H, L)}{\mathcal{F}_{H}(\tau, H, L)}\right|_{H=\eta, L=1}\left(=\frac{\mathcal{F}_{L}(\tau, H, L)}{\mathcal{F}_{H}(\tau, H, L)} \forall(H, L) \in \mathbb{R}_{++}^{2} \mid \frac{H}{L}=\eta\right) .
$$

Let us now consider the cone of diversification in our economy (its formal derivation is relegated to the appendix). Note that it depends on the tax rate $\tau$, in other words, for each tax rate there is an associated cone. ${ }^{10}$ The cone is spanned by two vectors, $\left(\hat{H}^{c}(\tau), \hat{L}^{c}(\tau)\right),\left(\hat{H}^{d}(\tau), \hat{L}^{d}(\tau)\right)$ (described in Appendix) such that

$$
\hat{\eta}^{d}(\tau)<\hat{\eta}^{c}(\tau)
$$

where

$$
\hat{\eta}^{j}(\tau):=\frac{\hat{H}^{j}(\tau)}{\hat{L}^{j}(\tau)}, j=c, d
$$

is the ratio of human capital to unskilled labor in sector $j$ (recall that good $c$ is human capital-intensive). The value of $H / L$ in relation to $\hat{\eta}^{j}(\tau)$ determines whether the economy specializes or produces both goods:

- if $H / L \leq \hat{\eta}^{d}(\tau)$, then the solution to the maximization problem in (4) is "dirty" (the clean output is zero);

- if $\hat{\eta}^{d}(\tau)<H / L<\hat{\eta}^{c}(\tau)$, then the solution to the maximization problem in (4) is "mixed" (both clean and dirty outputs are positive);

- $H / L \geq \hat{\eta}^{c}(\tau)$, then the solution to the maximization problem in (4) is "clean" (the dirty output is zero).

It also follows that

$$
\begin{aligned}
& \mathcal{F}(\tau, H, L)=(1-\tau) F^{d}(H, L), \text { if } \frac{H}{L} \leq \hat{\eta}^{d}(\tau), \\
& \mathcal{F}(\tau, H, L)=F^{c}(H, L), \text { if } \frac{H}{L}>\hat{\eta}^{c}(\tau) .
\end{aligned}
$$

If $(H, L)$ lies within the cone of diversification, then, by the factor price equalization theorem, the wage rates of human capital and unskilled labor (equal to $\mathcal{F}_{H}(\tau, H, L)$ and $\mathcal{F}_{L}(\tau, H, L)$, respectively) are fully determined by the tax rate. Denote them by $w^{H}(\tau)$ and $w^{L}(\tau)$ and note that the ratio $w^{H}(\tau) / w^{L}(\tau)$ is continuous and increasing in $\tau$.

It is clear that

$$
\xi^{j}\left(\hat{\eta}^{j}(\tau)\right)=\frac{w^{L}(\tau)}{w^{H}(\tau)}, j=c, d
$$

which we may write as ${ }^{11}$

$$
\hat{\eta}^{j}(\tau)=\left(\xi^{j}\right)^{-1}\left(\frac{w^{L}(\tau)}{w^{H}(\tau)}\right), j=c, d
$$

Hence, $\hat{\eta}^{j}(\tau), j=c, d$, are continuous and decreasing functions of $\tau$ because $w^{H}(\tau) / w^{L}(\tau)$ is continuous and increasing in $\tau$. Thus

$$
\xi(\tau, \eta)=\left\{\begin{array}{lll}
\xi^{d}(\eta), & \text { if } \quad \eta<\hat{\eta}^{d}(\tau) \\
w^{L}(\tau) / w^{H}(\tau), & \text { if } \quad \hat{\eta}^{d}(\tau) \leq \eta \leq \hat{\eta}^{c}(\tau) \\
\xi^{c}(\eta), & \text { if } \eta>\hat{\eta}^{c}(\tau)
\end{array}\right.
$$

In (8), the domain where $\xi(\tau, \eta)=\xi^{d}(\eta)$ corresponds to the case of dirty output, the domain where $\xi(\tau, \eta)=w^{L}(\tau) / w^{H}(\tau)$ to the mixed case with both clean and dirty outputs positive, and the domain where $\xi(\tau, \eta)=\xi^{c}(\eta)$ to the case of clean output. These relationships complete the characterization of the diversification pattern. We are now in the position to analyze the short-run equilibrium.

\footnotetext{
10 Strictly speaking, the cone of diversification exists only for $\tau \in\left(\tau^{\prime}, \tau^{\prime \prime}\right)$, where the detailed definition of the interval boundaries are provided in the appendix.

11 Here $\left(\xi^{j}\right)^{-1}(\cdot)$ denotes the inverse function of $\xi^{j}(\cdot)$.
} 


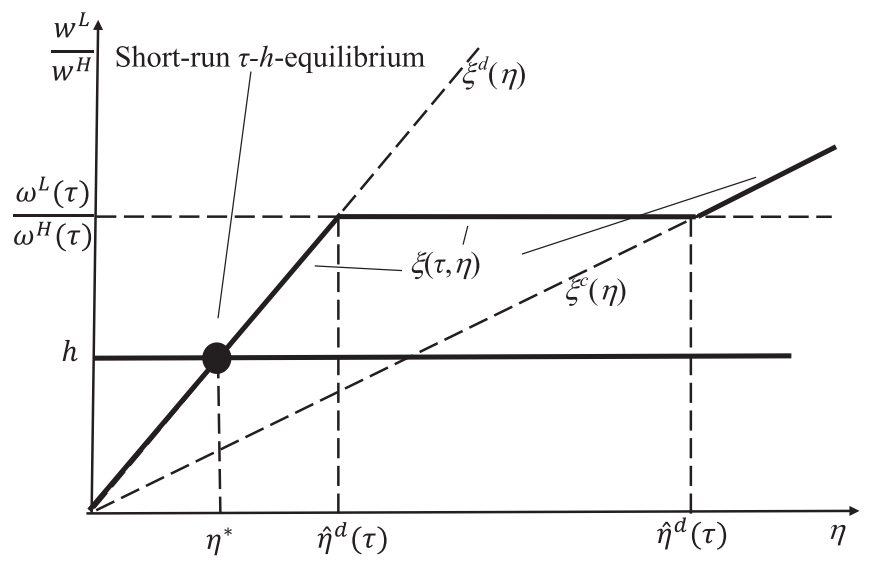

Fig. 1. Dirty short-run equilibrium.

\subsection{Equilibrium characterization}

\subsubsection{Short-run equilibrium determination}

Consider a short-run $\tau$-h-equilibrium $\left\{H^{*}, L^{*}, H^{c *}, L^{c *}, H^{d *}, L^{d *}, w^{H *}, w^{L *}\right\}$. It follows from (5) that

$$
\frac{w^{L *}}{w^{H *}}=\xi\left(\tau, \eta^{*}\right),
$$

where $\eta^{*}=\frac{H^{*}}{L^{*}}$ is the equilibrium level of aggregate human capital-to-unskilled labor ratio. The short-run relative supply of human capital is given by

$$
\frac{w^{L *}}{w^{H *}}=h
$$

Thus to find $\eta^{*}$ it is sufficient to solve the following equation:

$$
\xi(\tau, \eta)=h .
$$

Fig. 1 shows the function $\xi(\tau, \eta)$ for a given $\tau$ and illustrates this equation. The right-hand side is shown by the horizontal line at $\frac{w^{L}}{w^{H}}=h$ on the vertical axis, representing the short-run labor supply. The left-hand side is shown by the kinked bold line, which coincides with the $\xi^{d}(\eta)$-schedule for $\eta<\hat{\eta}^{d}(\tau)$, with $\frac{w^{L}(\tau)}{w^{H}(\tau)}$ for $\hat{\eta}^{d}(\tau) \leqslant \eta \leqslant \hat{\eta}^{c}(\tau)$, and with the $\xi^{c}(\eta)$-schedule for $\eta>\hat{\eta}^{c}(\tau)$. The solution to (9) is unique if $h \neq w^{L}(\tau) / w^{H}(\tau)$ (otherwise the set of solutions is the interval [ $\hat{\eta}^{d}(\tau)$, $\left.\hat{\eta}^{c}(\tau)\right]$ ). As an example, we show the solution for the case of a dirty short-run $\tau$-h-equilibrium, denoted by $\eta^{*}$ in the figure.

Note that a short-run $\tau$-h-equilibrium $\left\{H^{*}, L^{*}, H^{c *}, L^{c *}, H^{d *}, L^{d *}, w^{H *}, w^{L *}\right\}$ is fully characterized by the equilibrium aggregate human capital-to-unskilled labor ratio, $\eta^{*}=H^{*} / L^{*}$. Indeed, taking account of the equality $H^{*} / h+L^{*}=1$, we have

$$
L^{*}=\frac{h}{h+\eta^{*}}, H^{*}=\frac{h \eta^{*}}{h+\eta^{*}}
$$

Then, knowing $\left(H^{*}, L^{*}\right)$, we can easily obtain $\left(H^{c *}, L^{c *}\right),\left(H^{d *}, L^{d *}\right), w^{H *}$ and $w^{L *}$. For convenience, we will refer from now on to a short-run $\tau$-h-equilibrium as the equilibrium value of the aggregate human capital-to-unskilled labor ratio, $\eta^{*}$. We formulate the following proposition characterizing short-run equilibria.

Proposition 1. Suppose we are given a $\tau \geq 0$ from the interval $\left(\tau^{\prime}, \tau^{\prime \prime}\right)$.

1) If $h<w^{L}(\tau) / w^{H}(\tau)$, then there is a unique short-run $\tau$-h-equilibrium $\eta^{*}$. This equilibrium is dirty and determined by

$$
\eta^{*}=\left(\xi^{d}\right)^{-1}(h) \text {. }
$$

2) If $h=w^{L}(\tau) / w^{H}(\tau)$, then any $\eta^{*}$ from the interval $\left[\hat{\eta}^{d}(\tau), \hat{\eta}^{c}(\tau)\right]$ is a short-run $\tau$-h-equilibrium. In this equilibrium, except for the cases where $\eta^{*}=\hat{\eta}^{d}(\tau)$ and $\eta^{*}=\hat{\eta}^{c}(\tau)$, both outputs, dirty and clean, are positive.

3) If $h>w^{L}(\tau) / w^{H}(\tau)$, then there is a unique short-run $\tau$-h-equilibrium $\eta^{*}$. This equilibrium is clean and determined by

$$
\eta^{*}=\left(\xi^{c}\right)^{-1}(h)
$$

Proof. See the Appendix. 
3.3.2. Role of the carbon tax

To highlight the role of the carbon tax let us consider again the following equation:

$$
\frac{w^{L}(\tau)}{w^{H}(\tau)}=h
$$

The ratio $w^{L}(\tau) / w^{H}(\tau)$ is decreasing in $\tau$ and hence the solution to this equation is unique, we denote it by $\tau(h)$. In other words, the $\tau(\cdot)$ function is inverse to $w^{L}(\cdot) / w^{H}(\cdot)$. Therefore it is continuous and decreasing ${ }^{12}$. It is important to note that the link between the tax rate and human capital is given by

$$
\tau>\tau(h) \Leftrightarrow h>\frac{w^{L}(\tau)}{w^{H}(\tau)}, \tau=\tau(h) \Leftrightarrow h=\frac{w^{L}(\tau)}{w^{H}(\tau)}, \tau<\tau(h) \Leftrightarrow h<\frac{w^{L}(\tau)}{w^{H}(\tau)} .
$$

Therefore, we may formulate the following

Proposition 2. Suppose we are given an $h>0$ and $\tau \geq 0$.

1) If $\tau<\tau(h)$ (or, equivalently $h<w^{L}(\tau) / w^{H}(\tau)$ ), then there is a unique short-run $\tau$-h-equilibrium $\eta^{*}$. This equilibrium is dirty and determined by

$$
\eta^{*}=\left(\xi^{d}\right)^{-1}(h) .
$$

2) if $\tau=\tau(h)$ (or, equivalently $h=w^{L}(\tau) / w^{H}(\tau)$ ), then any $\eta^{*}$ from the interval $\left[\left(\xi^{d}\right)^{-1}(h),\left(\xi^{c}\right)^{-1}(h)\right]$ is a short-run $\tau$-h-equilibrium. In this equilibrium, except for the cases where $\eta^{*}=\hat{\eta}^{d}(\tau)$ and $\eta^{*}=\hat{\eta}^{c}(\tau)$, the output in both sectors is positive.

3) If $\tau>\tau(h)$ (or, equivalently $h>w^{L}(\tau) / w^{H}(\tau)$ ), then there is a unique short-run $\tau$-h-equilibrium $\eta^{*}$. This equilibrium is clean and determined by

$$
\eta^{*}=\left(\xi^{c}\right)^{-1}(h)
$$

Proof. See the Appendix.

Fig. 1 illustrates the first of the three possible cases described in the above proposition. In the figure the short-run equilibrium is dirty, because $h<w^{L}(\tau) / w^{H}(\tau)$. However, if we increase $\tau, w^{L}(\tau) / w^{H}(\tau)$ will go down and for $\tau$ sufficiently high we will have $h>w^{L}(\tau) / w^{H}(\tau)$ and hence the short-run equilibrium will become clean.

\subsubsection{Link to GDP}

Next we ask the following question: What is the dependence of the equilibrium GDP on $h$ for a given $\operatorname{tax} \tau \geq 0$ ? We know from Proposition 2 that when $h<w^{L}(\tau) / w^{H}(\tau)$, the short-run $\tau$-h-equilibrium is equal to $\left(\xi^{d}\right)^{-1}(h)$ and, taking account of (10), GDP in this equilibrium is equal to

$$
Y^{d}(h):=F^{d}\left(\frac{h \cdot\left(\xi^{d}\right)^{-1}(h)}{h+\left(\xi^{d}\right)^{-1}(h)}, \frac{h}{h+\left(\xi^{d}\right)^{-1}(h)}\right) .
$$

Analogously, when $h>w^{L}(\tau) / w^{H}(\tau)$, the equilibrium GDP is equal to

$$
Y^{c}(h):=F^{c}\left(\frac{h \cdot\left(\xi^{c}\right)^{-1}(h)}{h+\left(\xi^{c}\right)^{-1}(h)}, \frac{h}{h+\left(\xi^{c}\right)^{-1}(h)}\right) .
$$

Note that $Y^{d}(h)$ and $Y^{c}(h)$ are well defined for all positive $h$. When $h=w^{L}(0) / w^{H}(0)$, the set of all short-run $\tau$-h-equilibria is the interval $\left[\left(\xi^{d}\right)^{-1}(h),\left(\xi^{c}\right)^{-1}(h)\right]$ and hence, by the continuity argument, the set of equilibrium levels of GDP is the interval consisting of all values lying between $Y^{d}(h)$ and $Y^{c}(h)$.

\section{Proposition 3.}

1) The functions $Y^{d}(h)$ and $Y^{c}(h)$ are increasing.

2) The following equality holds true:

$$
\frac{Y^{c}(h)}{Y^{d}(h)}=1-\tau(h)
$$

Hence the proportion $Y^{c}(h) / Y^{d}(h)$ is also increasing in $h$ and $Y^{c}(h)=Y^{d}(h)$ for $h=w^{L}(0) / w^{H}(0)$.

Proof. See the Appendix.

Thus, for a given $\tau \geq 0$, the dependence of the level of GDP in $\tau$-h-equilibria on $h$ is characterized as follows ${ }^{13}$ :

\footnotetext{
12 It is possible to show that due to the Inada condition, $w^{L}(\tau) / w^{H}(\tau) \rightarrow \infty$ as $\tau \rightarrow \tau^{\prime}$ and $w^{L}(\tau) / w^{H}(\tau) \rightarrow 0$ as $\tau \rightarrow \tau^{\prime \prime}$. Therefore, the $\tau(\cdot)$ function is defined on $(0, \infty)$, and $\tau(h) \underset{h \rightarrow 0}{\longrightarrow} \tau^{\prime \prime}, \tau(h) \underset{h \rightarrow \infty}{\longrightarrow} \tau^{\prime}$.

${ }^{13}$ By footnote ${ }^{13}$, if $\tau^{\prime \prime}=1$, then $\tau(h) \rightarrow 1$ and hence $Y^{c}(h) / Y^{d}(h) \rightarrow 0$ as $h \rightarrow 0$.
} 


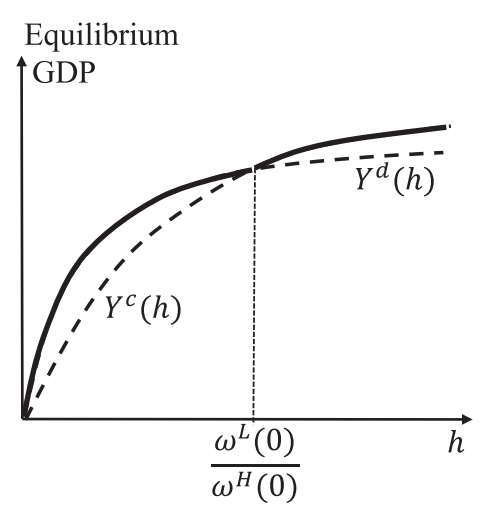

a) $\tau=0$

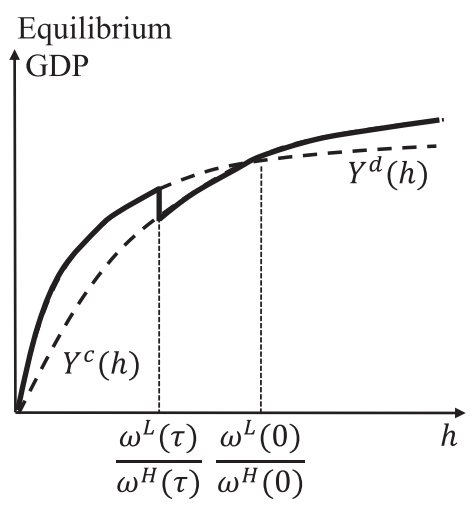

b) $\tau>0$

Fig. 2. Equilibrium (pre-tax) GDP with zero and positive carbon tax. The dashed lines show the functions $Y^{d}(h)$ and $Y^{c}(h)$ (the outputs if only one of the two technologies were active). The solid line shows the output in equilibrium.

- If $\tau=0$, then GDP is increasing in $h$;

- If $\tau>0$, then GDP is increasing in $h$ on the intervals $\left(0, w^{L}(\tau) / w^{H}(\tau)\right)$ and $\left(w^{L}(\tau) / w^{H}(\tau), \infty\right)$, but exhibits a drop at $h=w^{L}(\tau) / w^{H}(\tau)$. In percentage terms this drop increases as $h$ decreases (up to $100 \%$ if $\tau^{\prime \prime}=1$ ).

The dependence of the level of pre-tax GDP in $\tau$-h-equilibria on $h$ is depicted in Fig. 2 . In panel a) of this figure the tax rate is taken to be zero and in panel $b) \tau>0$.

Now suppose that we are given an $h$ lower than $w^{L}(0) / w^{H}(0)$. If there is no carbon tax, then, by Proposition 2 , the only $\tau$ $h$-equilibrium is dirty and equal to $\hat{\eta}^{d}(\tau(h))$. In order to push the economy to a clean equilibrium, it is sufficient to impose a tax $\tau>0$ on the dirty output. If this tax is higher than $\tau(h)$, the economy will switch to a clean short-run equilibrium, namely, to $\hat{\eta}^{c}(\tau(h))$. Proposition 3 tells us that this switch will happen not without some loss of GDP. What is the size of the loss? In percentage terms it is equal to $\tau(h)$. Thus, if the level of human capital in the economy is sufficiently high ( $h$ is close to $\left.w^{L}(0) / w^{H}(0)\right)$, it is not so big. However, if $h$ is small, this loss may be prohibitively large.

\section{Equilibrium dynamics}

Now we turn to the equilibrium dynamics in our model. The dynamics of the model are represented by the development of the human capital to labor ratio, $\eta$, and can be summarized as follows. The economy starts with a given human capital, $H_{t-1}$, and an input ratio $\eta_{t-1}$. The stock $H_{t-1}$ determines individual human capital, $h_{t}$, by the individual household education decision. This then fixes the relative wage for skilled labor, $w_{H} / w_{L}$, by the arbitrage education decision. For a given tax $\tau$ this determines the number of agents who decide to educate from which we get $H_{t}$ and $\eta_{t}$. The rest of this section describes the mechanism formally.

\subsection{Dynamics}

Let $\tau \geq 0$ be given. Suppose that at time $t$ the effective human capital of a skilled agent is $h_{t}$. Then a short-run $\tau$ - $h_{t^{-}}$ equilibrium, $\eta_{t}$, is determined by

$$
h_{t}=\xi\left(\tau, \eta_{t}\right) .
$$

Knowing $\eta_{t}$, we can calculate $H_{t}$ and $h_{t+1}$ : By (10), we have

$$
H_{t}=\frac{\xi\left(\tau, \eta_{t}\right) \eta_{t}}{\xi\left(\tau, \eta_{t}\right)+\eta_{t}}
$$

and by (1)

$$
h_{t+1}=\psi\left(\frac{\xi\left(\tau, \eta_{t}\right) \eta_{t}}{\xi\left(\tau, \eta_{t}\right)+\eta_{t}}\right)
$$

or, for short,

$$
h_{t+1}=\phi\left(\tau, \eta_{t}\right),
$$

where the function $\phi:[0,1) \times \mathbb{R}_{++}$is defined as

$$
\phi(\tau, \eta):=\psi\left(\frac{\xi(\tau, \eta) \eta}{\xi(\tau, \eta)+\eta}\right) .
$$


In each time period the $\phi(\tau, \cdot)$ function shows the level of effective human capital of a skilled agent as a function of the aggregate human-capital-to-unskilled-labor ratio in the previous period.

We define an equilibrium path as a sequence $\left(h_{t}, \eta_{t}\right)_{t=0}^{\infty}$, for a given $h_{0}>0$, by the condition that for all $t=0,1, \ldots, \eta_{t}$ is a short-run $\tau$-ht $h_{t}$-equilibrium ((12) holds true) and $h_{t+1}$ is determined by (13). For ease of exposition we will focus only on the sequence $\left(\eta_{t}\right)_{t=0}^{\infty}$, which satisfies for all $t=0,1, \ldots$, the following recursive equation:

$$
\xi\left(\tau, \eta_{t+1}\right)=\phi\left(\tau, \eta_{t}\right) .
$$

Definition 2. Suppose we are given an initial level of effective human capital of a skilled agent, $h_{0}>0$. A sequence of the aggregate human capital-to-unskilled labor ratios, $\left(\eta_{t}\right)_{t=0}^{\infty}$, determined by $h_{0}=\xi\left(\tau, \eta_{0}\right)$ and for $t=1,2, \ldots$, by (14) is called a $\tau$-equilibrium path starting from $h_{0}$.

It is noteworthy that, by (8),

$$
\phi(\tau, \eta)=\left\{\begin{array}{lll}
\psi\left(\frac{\xi^{d}(\eta) \eta}{\xi^{d}(\eta)+\eta}\right), & \text { if } \quad \eta<\hat{\eta}^{d}(\tau) \\
\psi\left(\frac{w^{L}(\tau) \eta}{w^{L}(\tau)+w^{H}(\tau) \eta}\right), & \text { if } & \hat{\eta}^{d}(\tau) \leq \eta \leq \hat{\eta}^{c}(\tau) \\
\psi\left(\frac{\xi^{c}(\eta) \eta}{\xi^{c}(\eta)+\eta}\right), & \text { if } & \eta>\hat{\eta}^{c}(\tau) .
\end{array}\right.
$$

It follows from (2) that $\frac{\xi^{d}(\eta) \eta}{\xi^{d}(\eta)+\eta}>\frac{\xi^{c}(\eta) \eta}{\xi^{c}(\eta)+\eta}$. Taking account of the monotonicity of the $\psi(\cdot)$ function we obtain that

$$
\psi\left(\frac{\xi^{d}(\eta) \eta}{\xi^{d}(\eta)+\eta}\right)>\psi\left(\frac{\xi^{c}(\eta) \eta}{\xi^{c}(\eta)+\eta}\right)
$$

and that $\phi(\tau, \eta)$ is increasing in $\eta$.

\subsection{Steady-state equilibria and convergence}

Now we turn to the discussion of steady-state equilibria (SSE) in our economy.

Definition 3. Let $\tau \geq 0$ from the interval $\left(\tau^{\prime}, \tau^{\prime \prime}\right)$ be given. A solution to the equation

$$
\xi(\tau, \eta)=\phi(\tau, \eta)
$$

is called a $\tau$-steady-state equilibrium ( $\tau$-SSE).

To provide a complete characterization of SSE and the dynamics of equilibrium paths in what follows we make the following assumption:

\section{Assumption 3.}

$$
\frac{d}{d \eta} \psi\left(\frac{\xi^{j}(\eta) \eta}{\xi^{j}(\eta)+\eta}\right)<\frac{d}{d \eta} \xi^{j}(\eta) \forall \eta>0, j=c, d .
$$

The assumption requires the slope of the $\psi(\cdot)$ function to be smaller than the slope of the $\xi(\tau, \cdot)$ function along the clean and the dirty subsets. This guarantees stability of the two equilibria in which the economy is specialized (i.e. either clean or dirty). If the production functions are Cobb-Douglas, i.e. given by (3), then

$$
\frac{\xi^{j}(\eta) \eta}{\xi^{j}(\eta)+\eta}=\left(1-\alpha^{j}\right) \eta, j=c, d
$$

and, since the $\psi(\cdot)$ function is concave, Assumption 3 simplifies to

$$
\psi^{\prime}(0)<\frac{1-\alpha^{j}}{\alpha^{j}}, j=c, d
$$

We want to show that under Assumption 3 there are at most three types of $\tau$-SSE: the dirty, the clean and the intermediate. It follows from Assumption 3 that each of the following two equations,

$$
\psi\left(\frac{\xi^{d}(\eta) \eta}{\xi^{d}(\eta)+\eta}\right)=\xi^{d}(\eta)
$$

and

$$
\psi\left(\frac{\xi^{c}(\eta) \eta}{\xi^{c}(\eta)+\eta}\right)=\xi^{c}(\eta)
$$

has exactly one solution. We denote them by $\bar{\eta}^{d}$ and $\bar{\eta}^{c}$ and call the potential dirty and the potential clean SSE, respectively. They are natural candidates for being SSE and are characterized as follows: 
1) In the dirty potential SSE, $\bar{\eta}^{d}$, the number of unskilled workers is $\frac{\xi^{d}\left(\bar{\eta}^{d}\right)}{\xi^{d}\left(\bar{\eta}^{d}\right)+\bar{\eta}^{d}}$, the aggregate human capital level is $\frac{\xi^{d}\left(\bar{\eta}^{d}\right) \bar{\eta}^{d}}{\xi^{d}\left(\bar{\eta}^{d}\right)+\bar{\eta}^{d}}$, the effective human capital of a skilled agent is

$$
\bar{h}^{d}:=\psi\left(\frac{\xi^{d}\left(\bar{\eta}^{d}\right) \bar{\eta}^{d}}{\xi^{d}\left(\bar{\eta}^{d}\right)+\bar{\eta}^{d}}\right)
$$

and GDP is equal to $F^{d}\left(\frac{\xi^{d}\left(\bar{\eta}^{d}\right) \bar{\eta}^{d}}{\xi^{d}\left(\bar{\eta}^{d}\right)+\bar{\eta}^{d}}, \frac{\xi^{d}\left(\bar{\eta}^{d}\right)}{\xi^{d}\left(\bar{\eta}^{d}\right)+\bar{\eta}^{d}}\right)$.

2) In the clean potential SSE, $\bar{\eta}^{c}$, the number of unskilled workers is $\frac{\xi^{c}\left(\bar{\eta}^{c}\right)}{\xi^{c}\left(\bar{\eta}^{c}\right)+\bar{\eta}^{c}}$, the aggregate human capital level is $\frac{\xi^{c}\left(\bar{\eta}^{c}\right) \bar{\eta}^{c}}{\xi^{c}\left(\bar{\eta}^{c}\right)+\bar{\eta}^{c}}$, the effective human capital of a skilled agent is

$$
\bar{h}^{c}:=\psi\left(\frac{\xi^{c}\left(\bar{\eta}^{c}\right) \bar{\eta}^{c}}{\xi^{c}\left(\bar{\eta}^{c}\right)+\bar{\eta}^{c}}\right)
$$

and GDP is equal to $F^{c}\left(\frac{\xi^{c}\left(\bar{\eta}^{c}\right) \bar{\eta}^{c}}{\xi^{c}\left(\bar{\eta}^{c}\right)+\bar{\eta}^{c}}, \frac{\xi^{c}\left(\bar{\eta}^{c}\right)}{\xi^{c}\left(\bar{\eta}^{c}\right)+\bar{\eta}^{c}}\right)$.

Proposition 4. $\bar{\eta}^{d}<\bar{\eta}^{c}$ and $\bar{h}^{d}<\bar{h}^{c}$.

Proof. See the Appendix.

This proposition means that the aggregate human capital-to-unskilled labor ratio and the effective human capital of a skilled agent in the clean potential SSE are higher then in the dirty one. Noting that $\tau^{\prime}<\tau\left(\bar{h}^{c}\right)<\tau\left(\bar{h}^{d}\right)<\tau^{\prime \prime}$, we formulate the following proposition.

\section{Proposition 5.}

1) If

$$
\left.\bar{h}^{c}<\frac{w^{L}(\tau)}{w^{H}(\tau)} \text { (i.e. } \tau<\tau\left(\bar{h}^{c}\right)\right),
$$

then the potential dirty SSE is the only $\tau$-SSE in our economy and any $\tau$-equilibrium path converges to it.

2) If

$$
\left.\bar{h}^{d}<\frac{w^{L}(\tau)}{w^{H}(\tau)}<\bar{h}^{c} \text { (i.e. } \tau\left(\bar{h}^{c}\right)<\tau<\tau\left(\bar{h}^{d}\right)\right),
$$

then there are three $\tau$-SSE:

- the dirty SSE $\bar{\eta}^{d}$,

- the intermediate SSE $\eta^{m}(\tau)$ lying between $\hat{\eta}^{d}(\tau)$ and $\hat{\eta}^{c}(\tau)$,

- the clean SSE $\bar{\eta}^{c}$.

The dirty and the clean SSE, $\bar{\eta}^{d}$ and $\bar{\eta}^{c}$, are locally asymptotically stable and the equilibrium $\eta^{m}(\tau)$ is unstable. More precisely:

- if $h_{0}<\frac{w^{L}(\tau)}{w^{H}(\tau)}$, then the $\tau$-equilibrium path starting from $\eta_{0}$ is dirty (i.e. only the dirty technology is used from the beginning) and it converges to $\bar{\eta}^{d}$,

- if $h_{0}>\frac{w^{L}(\tau)}{w^{H}(\tau)}$, then the $\tau$-equilibrium path starting from $\eta_{0}$ is clean (i.e. only the clean technology is used from the beginning) and it converges to $\bar{\eta}^{c}$.

3) If

$$
\left.\frac{w^{L}(\tau)}{w^{H}(\tau)}<\bar{h}^{d} \text { (i.e. } \tau\left(\bar{h}^{d}\right)<\tau\right),
$$

then the potential clean SSE is the only $\tau$-SSE in our economy and any $\tau$-equilibrium path converges to it.

Proof. See the Appendix.

The three cases described in the above proposition are illustrated in Figs. 3, 4, 5. In Fig. 3, it is assumed that $\bar{h}^{c}<$ $w^{L}(\tau) / w^{H}(\tau)$ (i.e. $\tau<\tau\left(\bar{h}^{c}\right)$ ). In Fig. 4, the tax rate is higher than in Fig. 3; it satisfies the inequalities $\bar{h}^{d}<w^{L}(\tau) / w^{H}(\tau)<$ $\bar{h}^{c}$ (i.e. $\tau\left(\bar{h}^{c}\right)<\tau<\tau\left(\bar{h}^{d}\right)$ ). In Fig. 5, we illustrate the case where $w^{L}(\tau) / w^{H}(\tau)<\bar{h}^{d}$ (i.e. $\left.\tau\left(\bar{h}^{d}\right)<\tau\right)$ ).

It is worth noting that in the case where (18) holds true, but the initial aggregate human capital level is sufficiently high, initially the clean technology is used but the economy settles on a path of human capital decumulation and eventually the 


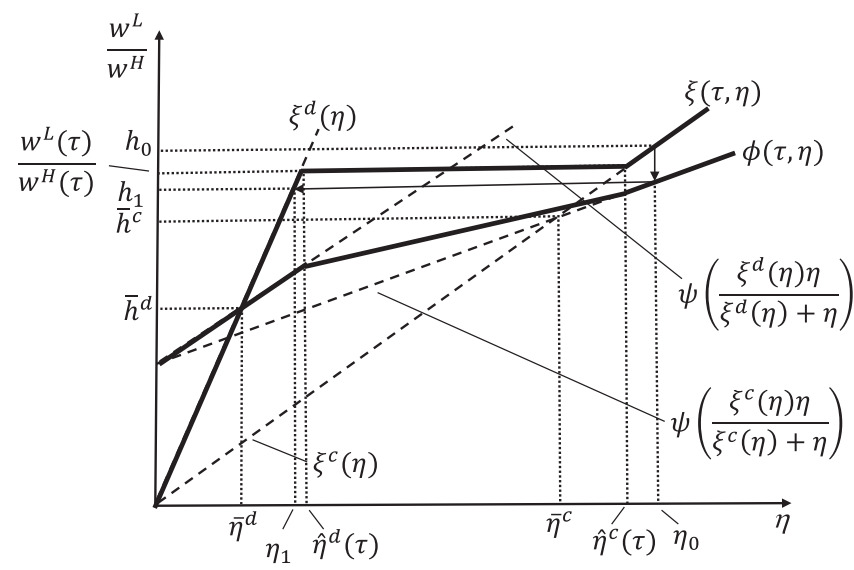

Fig. 3. The unique dirty $\tau$-steady-state equilibrium.

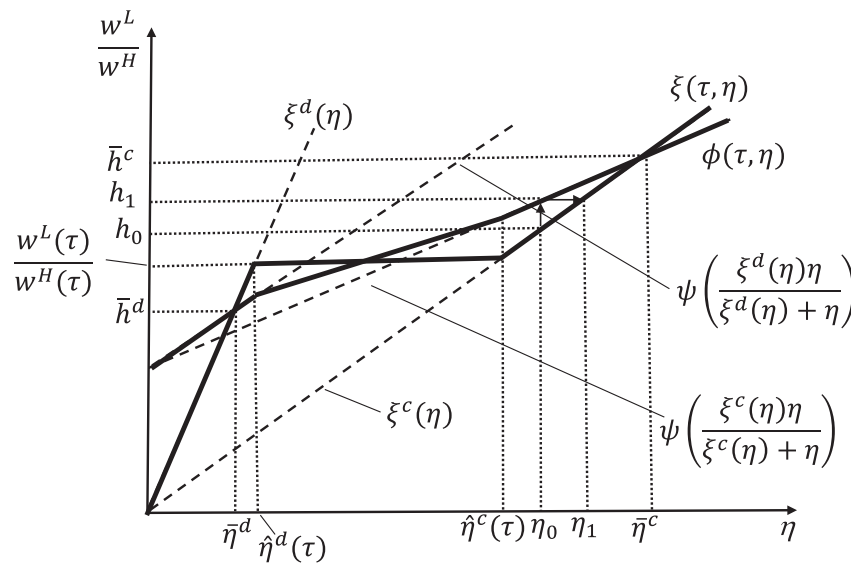

Fig. 4. Multiple $\tau$-steady-state equilibria.

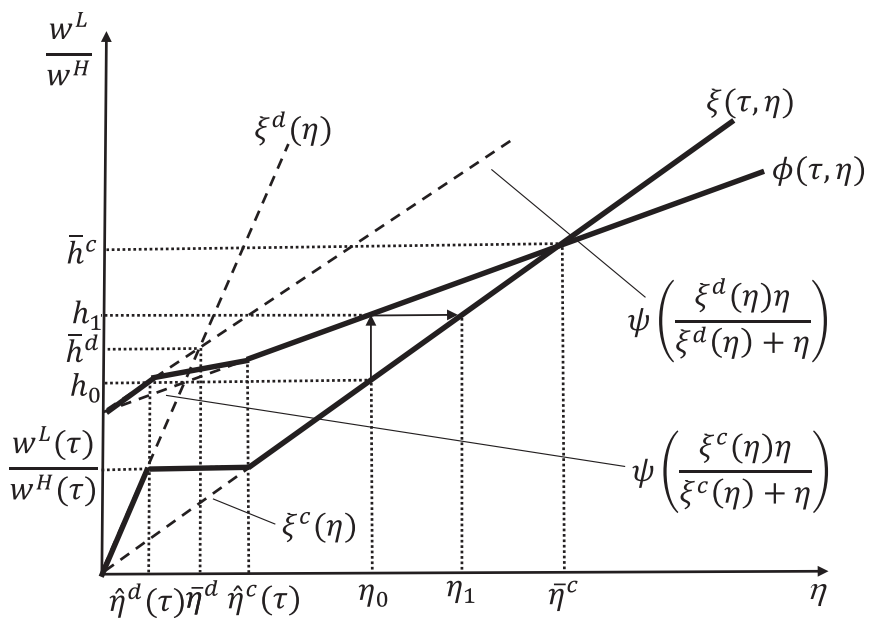

Fig. 5. The unique clean $\tau$-steady-state equilibrium.

dirty technology is used. In the case where (20) holds true, but the initial aggregate human capital level is sufficiently low, initially the dirty technology is used but the economy settles on the path of human capital accumulation and eventually the clean technology is used. In the case where (19) holds true and $w^{L}(\tau) / w^{H}(\tau) \neq \xi\left(\eta_{0}\right)$, the equilibrium path is from the beginning either clean or dirty depending on whether $w^{L}(\tau) / w^{H}(\tau)>\xi\left(\eta_{0}\right)$ or $w^{L}(\tau) / w^{H}(\tau)<\xi\left(\eta_{0}\right)$.

Observe that since $\xi(\tau, \eta)$ is non-decreasing and $\phi(\tau, \eta)$ is increasing in $\eta$, any equilibrium path $\left(\eta_{t}\right)_{t=0}^{\infty}$ (except those starting from and staying in SSE) is monotonically increasing $\left(\eta_{t+1}>\eta_{t}, t=0,1, \ldots\right)$ or decreasing $\left(\eta_{t+1}<\eta_{t}, t=0,1, \ldots\right)$. 


\subsection{Carbon tax and technology switch}

Propositions 3 and 5 help us understand the impact of a carbon tax on the dynamics of the economy.

In the case where, quite unrealistically, $w^{L}(0) / w^{H}(0)<\bar{h}^{d}$ (i.e. $\tau\left(\bar{h}^{d}\right)<0<\tau^{\prime \prime}$ ), the transition to clean technology happens in itself without any carbon tax. Even if the initial level of human capital is sufficiently low, the process of human capital accumulation eventually leads to a switch to the clean technology.

Now consider the case where $\bar{h}^{d}<w^{L}(0) / w^{H}(0)<\bar{h}^{c}$ (i.e. $\tau\left(\bar{h}^{c}\right)<0<\tau\left(\bar{h}^{d}\right)$ ), and hence by Proposition 3, GDP in the clean SSE is higher than in the dirty SSE:

$$
Y^{c}\left(\bar{h}^{c}\right)>Y^{d}\left(\bar{h}^{d}\right) \text {. }
$$

If the initial level of human capital is sufficiently high $\left(h_{0}>w^{L}(0) / w^{H}(0)\right)$, then the economy settles on a clean path from the beginning. Again, in this case no carbon tax is needed.

If the initial level of human capital is low $\left(h_{0}<w^{L}(0) / w^{H}(0)\right)$, then without a carbon tax the economy converge to the dirty SSE. Thus, to ensure the convergence to the clean SSE, a carbon tax should be imposed, but only temporarily. It should be noted that just at the moment when the tax is imposed, the level of human capital jumps up and the economy switches to the clean technology, but GDP drops. By Proposition 3, in percentage terms this drop is equal to $\tau\left(h_{0}\right)$ and the required tax $\tau$ should be a little higher than $\tau\left(h_{0}\right)$. After that the process of human capital accumulation continues and at some time $t, h_{t}$ becomes higher than $w^{L}(0) / w^{H}(0)$ and hence the tax can be set equal to zero. It should be emphasized that eventually GDP becomes higher than before imposing of the tax.

In the case where $\bar{h}^{c}<w^{L}(0) / w^{H}(0)$ (i.e. $\tau^{\prime}<0<\tau\left(\bar{h}^{c}\right)$ ), with no carbon tax the economy converge to the dirty SSE from any initial state. To ensure the convergence to the clean SSE, a carbon tax should be imposed and can never be set equal to zero. Again, at the moment when the tax is imposed, GDP drops, but after that the process of human capital accumulation leads to a permanent increase in GDP. It should be noted that the inequality $\bar{h}^{c}<w^{L}(0) / w^{H}(0)$ does not necessarily imply that the level of GDP in the clean SSE is lower than in the dirty SSE and does not preclude the possibility that eventually GDP becomes higher than before imposing of the tax.

A comment about the moment when the tax should be imposed is warranted. It may be speculated that if $h_{0}$ is lower than $\bar{h}^{d}$, then imposing the tax can be postponed. Indeed, Proposition 3 tells us that in this case an immediate imposition of the tax will lead to a substantial drop in GDP. At the same time even without the tax the human capital accumulation will take place. When the effective human capital of a skilled agent reaches a vicinity of $\bar{h}^{d}$, the drop in GDP will be less traumatic. On the contrary, if $\bar{h}^{d}<h_{0}<\bar{h}^{c}$ the tax should be imposed immediately, because otherwise the process of human capital decumulation will start.

With respect to the permanent effect of temporary environmental policy our results relate to the technical change framework of Acemoglu et al. (2012), where the learning effects are assumed to be sector specific. Abstracting from distinct sectors or different technologies, various recent contributions (Golosov et al., 2014; Gerlagh and Liski, 2018) have found the need for permanent carbon taxes with a tax rate proportional to output. A direct comparison of our model to that literature is not possible because we introduce different technologies but do not explicitly model the damages of climate change. When a single instrument, the carbon tax, has to correct for both the negative externalities of climate change and the positive learning spillovers in education it will have a higher rate than a pure environmental tax in the optimum. Also, as the potential drop in GDP at the moment of the technology switch is only temporary in our model, the optimum tax rate reflects the permanent gains in GDP and environmental quality after the drop.

\section{Model extensions}

\subsection{Endogenous growth set-up}

We now consider an endogenous-growth version of our model in which production is characterized by

$$
Y_{t}^{j}=A_{t} F^{j}\left(H_{t}^{j}, L_{t}^{j}\right), j=c, d,
$$

where $A_{t}$ is the total factor productivity. We posit an extended concept of learning effects by adding positive spillovers from human capital to total factor productivity so that the growth rate of TFP at each time depends positively on the amount of human capital accumulated by the economy up to that time. The assumption says that higher education standards in an economy raise not only learning productivity but also total factor productivity which is realistic. ${ }^{14}$ For simplicity, we assume that $A_{t}$ is equal for both technologies, so that

$$
A_{t}=G\left(H_{t-1}\right) A_{t-1}
$$

with $G(\cdot)$ being a continuous increasing function.

The slight modification of the setup does not alter our basic statements, all above definitions are applicable and all proved results hold true. The main difference is that now higher levels of human capital lead to higher growth of the economy. In

\footnotetext{
14 In the infinite horizon approach of Lucas (1988) positive human capital spillovers in final goods production act like an increase of total factor productivity; in our multi-generation setup the two effects are different.
} 
particular, the clean SSE is characterized by a higher growth rate than the dirty SSE. It follows that imposing the carbon tax and inducing a switch of the economy to a clean path increases the rate of growth, which makes our results even more appealing for policy makers. Therefore, the conclusion that levying the carbon tax eventually makes GDP higher than before the tax is unambiguously correct irrespective of whether $\bar{h}^{c}$ is higher or lower than $w^{L}(0) / w^{H}(0)$.

\subsection{North-south set-up}

Now we extend our model to an asymmetric two-country setting. We wish to study the consequences of human capital spillovers from one country, presumably more advanced, to the other. The question of knowledge and technology transfer from the developed to the developing countries has been a controversial topic, intensified by the discussion of the impacts of climate change. On the one hand, the technological gap between the so-called North and the so-called South made it obvious that the South's ability to mitigate and to adapt to climate change is severely hampered. During climate Conferences of the Parties, representatives of these countries have regularly expressed the view that the "rich" North should offer its help if it expects any cooperation on the climate policy. This help should, presumably, include a transfer of technological know-how allowing the South to adopt green production processes and be able to implement climate-change adaptation measures. On the other hand, such know-how is often protected by patent rights and is the property of individual firms who are reluctant to simply "give away" their technology. In this section we show that human capital spillovers from the developed to the developing economies have far-reaching consequences for clean technology adoption in the South and its growth convergence. Such a spillover may be generated through governmental educational programs, for example by allowing students from the developing economies to study in the universities of the advanced economies under the condition of subsequent return to the home country.

Suppose that the world consists of two countries, North and South, each described by the model of Section 2, except for the process of human capital accumulation in the South, which is described below. We shall assume that there is a positive human capital spillover from $\mathrm{N}$ to $\mathrm{S}$, so that

$$
h_{t}^{S}=\psi^{S}\left(H_{t-1}^{S}, H_{t-1}^{N}\right)
$$

and that $\psi^{S}\left(H^{S}, H^{N}\right)$ is increasing in both $H^{S}$ and $H^{N}$. Then the function $\phi^{S}$ can be written as $\phi^{S}\left(\tau, \eta^{S}, \eta^{N}\right)$.

In this case the transition of the North to the clean SSE and the accumulation of human capital in the North will shift the $\phi^{S}\left(\tau, \eta^{S}, \cdot\right)$ curve upwards. This shift will lead to widening of the domain of convergence to the clean SSE in the South.

Now assume that the production functions are of the form

$$
Y_{t}^{j}=A_{t} F^{j}\left(H_{t}^{j}, L_{t}^{j}\right), j=c, d,
$$

where the TFP $A_{t}$ is common for the two sectors but different across countries:

$$
A_{t}^{N}=G^{N}\left(H_{t-1}^{N}\right) A_{t-1}^{N}
$$

and

$$
A_{t}^{S}=G^{S}\left(H_{t-1}^{S}\right) B\left(A_{t-1}^{N}, A_{t-1}^{S}\right) .
$$

While the dynamics of TFP in the North are identical to those in Section 5, the dynamics of TFP in the South benefit from the TFP level in the North (again, through a positive spillover), as in Bretschger and Suphaphiphat (2014). In this case, human capital accumulation in the North indirectly benefits the South due to improvements in TFP. Consequently, the imposition of a carbon tax in the North and its effect on human capital formation causes a double positive effect in the South, i.e. by boosting human capital and by improving TFP growth. Then transition to the clean SSE in the North will increase the rate of growth in both the North and the South and the transition to the clean SSE in the South will help the South to catch up with the North.

\section{Conclusions}

Policy debate over carbon taxation and environmental regulation often focuses on the short term costs and downplays the long-term benefits. In this paper we highlight an important and often overlooked dimension of carbon pricing related to the effect of transiting from dirty to clean technology on human capital formation, with its overall benefit for the TFP growth.

We have presented a dynamic model featuring the interactions among carbon pricing, technology transition and human capital accumulation. Our main results may be summarized as follows. Imposition of a carbon tax may induce a switch from dirty to clean production techniques and lead to the economy settling permanently in the "clean" steady-state equilibrium. Because the clean sector is assumed to be skill-intensive, this transition is accompanied by growth in the aggregate human capital level through its intergenerational spillover effect. Moreover, the interesting feature of the carbon policy is that it only needs to be temporary. This is because the clean SSE is stable, so that once the transition to it has been accomplished, there is no more need to maintain a positive tax rate, i.e. the tax rate may in fact be chosen to decline over time. Moreover, since the aggregate human capital level positively affects the rate of TFP growth (as is typically assumed in the growth literature), the carbon policy boosts economic growth by inducing human capital accumulation. Finally, in the presence of intercountry 
knowledge spillovers, i.e. when human capital accumulation in one country, say the North, produces positive effects on human capital formation in another country (say the South), for example through international educational student exchange programs, the latter enjoys a double positive effect. Not only its aggregate human capital level increases (without the South actually implementing any policy), but its TFP growth rises as well inducing the "catching-up" effect with the North.

It is common in the literature to assume that dirty production techniques are associated with degradation of the natural environment, which in turn creates a disutility for individual agents. We have side-stepped the analysis of the evolution of the natural environment, although such an analysis may be easily incorporated in our model. Clearly, if the economy is initially on the dirty path and no carbon policy is in place, the quality of the environment will decline over time. In this case we obtain the same outcome as, for example, in Proposition 2 of Acemoglu et al. (2012), namely that environmental disaster is unavoidable. If, however, an appropriate carbon tax is introduced and technology transition is set in motion, environmental disaster can be avoided. Note that, contrary to the findings of Acemoglu et al. (2012) in Propositions 3 and 6, the avoidance of a disaster in our setup does not depend either on the degree of substitutability between inputs or on the subsidization of the education sector. This is due to the fact that human capital accumulation in our model exhibits intergenerational positive spillover. When separately introducing the environment into the model it would also be straightforward to add a positive relationship between the state of the environment and human capital accumulation, as suggested by Zivin and Neidell (2013). This would unambiguously strengthen our conclusions about the growth effects in the transition to clean technologies.

We have abstracted from an explicit damage function relating dirty output to some other model variable. This would not change our results on the human capital-induced switch of technologies. We would need such a pollution-damage link if we were to calculate welfare effects or an optimal carbon tax but this goes beyond the scope of this paper. The perfect substitution of the two technologies is omnipresent in natural resource and energy models with the notion of "backstop" technologies but it may be considered as an extreme assumption for the longer run. It is clear that imperfect substitution would complicate the analysis but we expect the basic mechanism to hold as long as the technology substitution is good which is a relatively mild assumption.

We have focused our contribution on the pollution intensity of production and the positive spillovers of human capital to identify a specific effect of carbon pricing. There are additional market failures associated with climate change such as underinvestment in research, imperfect capital markets, coordination failures, imperfect information, and misperceived cobenefits of climate policy (Stern (2015)) which are not considered in our approach. These might require the use of additional policy instruments or a different level and time profile of carbon pricing in the optimum. ${ }^{15}$ Our policy conclusions are valid in the context of education and human capital externalities while including additional market failures in the present setup would lead to additional complexity which we liked to avoid. Overall, we argue that carbon taxation brings about not only direct environmental benefits (e.g., in terms of reduced pollution and improved health) but also indirect positive effects on the economy through accumulation of the knowledge capital and increased total factor productivity.

\section{A. Appendix}

\section{Cone of diversification}

Let us describe the cone of diversification as depending on the tax rate $\tau$ and define the interval of tax rates for which the cone exists. To derive the cone of diversification we use the unit cost functions which show the dependence of the minimal cost to produce one unit of output in two sectors on the prices of human capital and unskilled labor, $w^{H}$ and $w^{L}$ :

$$
\begin{aligned}
& c^{c}\left(w^{H}, w^{L}\right):=\min _{H, L}\left\{w^{H} H+w^{L} L \mid F^{c}(H, L) \geq 1\right\}, \\
& c^{d}\left(w^{H}, w^{L}\right):=\min _{H, L}\left\{w^{H} H+w^{L} L \mid F^{d}(H, L) \geq 1\right\} .
\end{aligned}
$$

Consider the following system of two equations in $w^{H}$ and $w^{L}$ :

$$
\left\{\begin{array}{l}
c^{c}\left(w^{H}, w^{L}\right)=1 \\
c^{d}\left(w^{H}, w^{L}\right)=1-\tau
\end{array} .\right.
$$

If the system of equations (A.1) has a solution, this solution is unique. We denote it by $\left(w^{H}(\tau), w^{L}(\tau)\right)$. The following remark provides conditions for the existence of a solution to (A.1).

Remark 1. 1) If there exist $(H, L)$ such that $F^{c}(H, L)>(1-\tau) F^{d}(H, L)$, then there exists $\left(w^{H}, w^{L}\right)$ such that $c^{c}\left(w^{H}, w^{L}\right)<(1-$ $\tau) c^{d}\left(w^{H}, w^{L}\right)$. 2) If there exist $(H, L)$ such that $F^{c}(H, L)<(1-\tau) F^{d}(H, L)$, then there exists $\left(w^{H}, w^{L}\right)$ such that $c^{c}\left(w^{H}, w^{L}\right)>$ $(1-\tau) c^{d}\left(w^{H}, w^{L}\right)$. 3) If $F^{c}(H, L)>(1-\tau) F^{d}(H, L)$ for all $(H, L) \in \mathbb{R}_{+}^{2}$, then $c^{c}\left(w^{H}, w^{L}\right)<(1-\tau) c^{d}\left(w^{H}, w^{L}\right)$ for any

\footnotetext{
${ }^{15}$ Carbon prices in the presence of large risks and tipping points have recently been derived in a theoretical climate model by Bretschger and Vinogradova
} (2018). 
$\left(w^{H}, w^{L}\right) \in \mathbb{R}_{+}^{2}$. 4) If $F^{c}(H, L)<(1-\tau) F^{d}(H, L)$ for all $(H, L) \in \mathbb{R}_{+}^{2}$, then $c^{c}\left(w^{H}, w^{L}\right)>(1-\tau) c^{d}\left(w^{H}, w^{L}\right)$ for any $\left(w^{H}, w^{L}\right) \in$ $\mathbb{R}_{+}^{2}$. It follows that, a solution to (A.1) exists if and only if there exist $(H, L)$ such that $F^{c}(H, L)>(1-\tau) F^{d}(H, L)$ and $\left(H^{\prime}, L^{\prime}\right)$ such that $F^{c}\left(H^{\prime}, L^{\prime}\right)<(1-\tau) F^{d}\left(H^{\prime}, L^{\prime}\right)$.

Let

$\tau^{\prime}:=\inf \{\tau \mid$ a solution to (A.1) exists $\}, \tau^{\prime \prime}:=\sup \{\tau \mid$ a solution to (A.1) exists $\}$.

By totally differentiating the system (A.1) we obtain that the ratio $w^{H}(\tau) / w^{L}(\tau)$ is a continuous increasing function of $\tau$ on $\left(\tau^{\prime}, \tau^{\prime \prime}\right)$. Using Remark 1 and Assumption 2, we can easily check that $\tau^{\prime \prime}>0$. As for $\tau^{\prime}$, it can be either negative or nonnegative. Taking into account Remark 1 , we can note that if there is a vector $(H, L)$ such that $F^{d}(H, L)<F^{c}(H, L)$, then $\tau^{\prime}<0$. If the production functions $F^{d}(H, L)$ and $F^{c}(H, L)$ are Cobb-Douglas, then $\tau^{\prime}=-\infty$ and $\tau^{\prime \prime}=1$.

For a given $\tau \geq 0$ from the interval $\left(\tau^{\prime}, \tau^{\prime \prime}\right)$, let the vectors $\left(\hat{H}^{c}(\tau), \hat{L}^{c}(\tau)\right)$ and $\left(\hat{H}^{d}(\tau), \hat{L}^{d}(\tau)\right)$ be the solutions to the minimization problems in (A.1) and (A.2) at $\left(w^{H}, w^{L}\right)=\left(w^{H}(\tau), w^{L}(\tau)\right)$. It is clear that the cone of diversification is spanned by these two vectors and that it exists for any $\tau \geq 0$ from the interval $\left(\tau^{\prime}, \tau^{\prime \prime}\right)$.

Proof of Proposition 1. The proposition follows from (8) and the definition of short-run equilibrium.

Proof of Proposition 2. The proposition follows from Proposition 1 and (11).

Proof of Proposition 3. For $j=c, d$, consider the following maximization problem

$$
\max _{L, H} F^{j}(H, L) \text { s.t. } \frac{H}{h}+L=1,
$$

where $h>0$ is given. The first-order condition to this problem may be written as $h=\xi^{j}(H / L)$, or, equivalently, $H / L=$ $\left(\xi^{j}\right)^{-1}(h)$. Thus, to solve (A.4), it is sufficient to solve the following system of two equations:

$$
\frac{H}{h}+L=1, \frac{H}{L}=\left(\xi^{j}\right)^{-1}(h)
$$

Thus, the solution to (A.4) is given by

$$
H=\frac{h \cdot\left(\xi^{j}\right)^{-1}(h)}{h+\left(\xi^{j}\right)^{-1}(h)}, L=\frac{h}{h+\left(\xi^{j}\right)^{-1}(h)},
$$

and the optimal value of this problem is equal to

$$
Y^{j}(h)=F^{j}\left(\frac{h \cdot\left(\xi^{j}\right)^{-1}(h)}{h+\left(\xi^{j}\right)^{-1}(h)}, \frac{h}{h+\left(\xi^{j}\right)^{-1}(h)}\right) .
$$

Since the optimal value of (A.4) is, clearly, increasing in $h$, we conclude that $Y^{j}(h)$ is increasing in $h$. Now consider the following maximization problem

$$
\max _{L, H} \mathcal{F}(\tau, H, L) \text { s.t. } \frac{H}{h}+L=1 .
$$

Necessary and sufficient conditions for optimality for this problem are

$$
\xi(\tau, H / L)=h, \frac{H}{h}+L=1 .
$$

If $h=w^{L}(\tau) / w^{H}(\tau)$, i.e. $\tau=\tau(h)$, then, in view of $(8)$, the set of solutions to this system of equations consists of all $(H$, $L$ ) such that $\hat{\eta}^{d}(\tau) \leq H / L \leq \hat{\eta}^{c}(\tau)$ and $H / h+L=1$. For all $(H, L)$ from this set the set of solutions, the value of $\mathcal{F}(\tau, H, L)$ is the same. We are interested in two elements of the set of solutions of problem (A.5) at $\tau=\tau(h)$ : $\left(H^{\prime}, L^{\prime}\right)$ for which $H^{\prime} / L^{\prime}=$ $\hat{\eta}^{d}(\tau(h))\left(=\left(\xi^{d}\right)^{-1}(h)\right)$ and $\left(H^{\prime \prime}, L^{\prime \prime}\right)$ for which $H^{\prime \prime} / L^{\prime \prime}=\hat{\eta}^{c}(\tau(h))\left(=\left(\xi^{c}\right)^{-1}(h)\right)$. From (8) we obtain that $\xi^{d}\left(H^{\prime} / L^{\prime}\right)=h$ and $\xi^{c}\left(H^{\prime \prime} / L^{\prime \prime}\right)=h$ and hence,

$$
\begin{aligned}
& H^{\prime}=\frac{h \cdot\left(\xi^{d}\right)^{-1}(h)}{h+\left(\xi^{d}\right)^{-1}(h)}, L^{\prime}=\frac{h}{h+\left(\xi^{d}\right)^{-1}(h)}, \\
& H^{\prime \prime}=\frac{h \cdot\left(\xi^{c}\right)^{-1}(h)}{h+\left(\xi^{c}\right)^{-1}(h)}, L^{\prime \prime}=\frac{h}{h+\left(\xi^{c}\right)^{-1}(h)} .
\end{aligned}
$$


Therefore, by (6) and (7),

$$
\begin{aligned}
(1-\tau(h)) Y^{d}(h) & =(1-\tau(h)) F^{d}\left(\frac{h \cdot\left(\xi^{d}\right)^{-1}(h)}{h+\left(\xi^{d}\right)^{-1}(h)}, \frac{h}{h+\left(\xi^{d}\right)^{-1}(h)}\right)=\mathcal{F}\left(\tau, H^{\prime}, L^{\prime}\right) \\
& =\mathcal{F}\left(\tau, H^{\prime \prime}, L^{\prime \prime}\right)=F^{c}\left(\frac{h \cdot\left(\xi^{c}\right)^{-1}(h)}{h+\left(\xi^{c}\right)^{-1}(h)}, \frac{h}{h+\left(\xi^{c}\right)^{-1}(h)}\right)=Y^{c}(h) .
\end{aligned}
$$

Proof of Proposition 4. Suppose that $\bar{h}^{c} \leq \bar{h}^{d}$. Let $\tilde{\eta}$ be the solution to the equation $\xi^{d}(\eta)=\bar{h}^{c}$. By (2), $\tilde{\eta} \leq \bar{h}^{c}$ and hence $\tilde{\eta} \leq \bar{h}^{d}$. Taking into account the inequality $\psi(0)>0$ and Assumption 3, we have

$$
\bar{h}^{c}=\xi^{d}(\tilde{\eta}) \leq \psi\left(\frac{\xi^{d}(\tilde{\eta}) \tilde{\eta}}{\xi^{d}(\tilde{\eta})+\tilde{\eta}}\right)=\psi\left(\frac{\bar{h}^{c} \tilde{\eta}}{\bar{h}^{c}+\tilde{\eta}}\right) .
$$

Since the expression $\psi\left(\frac{\bar{h}^{c} \eta}{\bar{h}^{c}+\eta}\right)$ is increasing in $\eta$, we also have

$$
\psi\left(\frac{\bar{h}^{c} \tilde{\eta}}{\bar{h}^{c}+\tilde{\eta}}\right)<\psi\left(\frac{\bar{h}^{c} \bar{\eta}^{c}}{\bar{h}^{c}+\bar{\eta}^{c}}\right)=\psi\left(\frac{\xi^{c}\left(\bar{\eta}^{c}\right) \bar{\eta}^{c}}{\xi^{c}\left(\bar{\eta}^{c}\right)+\bar{\eta}^{c}}\right)=\bar{h}^{c} .
$$

Therefore, $\bar{h}^{c}<\bar{h}^{c}$, a contradiction. This proves that $\bar{h}^{d}<\bar{h}^{c}$. Taking account of (2), we also obtain the inequality $\bar{\eta}^{d}<\bar{\eta}^{c}$.

Proof of Proposition 5. First note that on the interval $\left(0, \bar{\eta}^{d}\right)$, the equation (15) is equivalent to the equation (16), on the interval $\left[\bar{\eta}^{d}, \bar{\eta}^{c}\right]$ this equation is equivalent to the equation

$$
\psi\left(\frac{w^{L}(\tau) \eta}{w^{L}(\tau)+w^{H}(\tau) \eta}\right)=w^{L}(\tau) / w^{H}(\tau),
$$

and on the interval $\left(\bar{\eta}^{c}, \infty\right)$, it is equivalent to the equation (17). This observations proves the statements of the proposition concerning the structure of SSE. The statements concerning their stability follow from the fact that $\xi(\tau, \eta)$ is non-decreasing and $\phi(\tau, \eta)$ increasing in $\eta$.

\section{References}

Acemoglu, D., Aghion, P., Bursztyn, L., Hemous, D., 2012. The environment and directed technical change. Am. Econ. Rev. 102 (1), $131-166$.

Aghion, P., Dechezleprêtre, A., Hémous, D., Martin, R., Reenen, J.V., 2016. Carbon taxes path dependency, and directed technical change: evidence from the auto industry. J. Polit. Econ. 124 (1), 1-51.

Ambec, S., Cohen, M.A., Elgie, S., Lanoie, P., 2013. The porter hypothesis at 20: can environmental regulation enhance innovation and competitiveness. Rev. Environ. Econ. Policy 7 (1), 2-22.

Bank, W., 2012. Inclusive Green Growth: The Pathway to Sustainable Development. The World Bank. Washington, DC.: The World Bank.

Borissov, K., Bretschger, L., 2018. Optimal Carbon Policies in a Dynamic Heterogenous World. Economics Working Paper Series 18/297, ETH Zurich.

Bosi, S., Ragot, L., 2013. On the optimal control of pollution in a human capital growth model. Math. Econ. Lett. 1 (1), 9-15.

Bovenberg, A.L., de Mooij, R., 1997. Environmental tax reform and endogenous growth. J. Public Econ. 63 (2), $207-237$.

Bovenberg, A.L., Smulders, S., 1995. Environmental quality and pollution-augmenting technological change in a two-sector endogenous growth model. J. Public Econ. 57, 369-391.

Bretschger, L., 2015. Energy prices, growth, and the channels in between: theory and evidence. Resour. Energy Econ. 39, $29-52$.

Bretschger, L., 2017. Equity and the convergence of nationally determined climate policies. Environ. Econ. Policy Stud. 19/1, 1-14.

Bretschger, L., Suphaphiphat, N., 2014. Effective climate policies in a dynamic north-south model. Eur. Econ. Rev. 69, 59-77.

Bretschger, L., Vinogradova, A., 2017. Human development at risk: Economic growth with pollution-induced health shocks. Environ. Resour. Econ. 66/3, 481-495.

Bretschger, L., Vinogradova, A., 2018. Escaping damocles' sword: endogenous climate shocks in a growing economy 18/291. Economics Working Paper Series ETH Zurich.

C., O.-F., Hinojosa, C., Miranda, G., 2010. Green jobs and skills: the local labour market implications of addressing climate change. Working document, CFE/LEED, OECD.

Consoli, D., Marin, G., Marzucchi, A., Vona, F., 2016. Do green jobs differ from non-green jobs in terms of skills and human capital? Res. Policy 45 (5), 1046-1060.

Cramton, P., MacKay, D.J.C., Ockenfels, A., Stoft, S., 2017. Global Carbon Pricing-The Path to Climate Cooperation. MIT Press.

De la, C.D., Doepke, M., 2003. Inequality and growth: why differential fertility matters. Am. Econ. Rev. 93 (4), $1091-1113$.

Dell, M., Jones, B.F., Olken, B.A., 2012. Temperature shocks and economic growth: evidence from the last half century. Am. Econ. J.: Macroecon. 4 (3), 66-95.

Gerlagh, R., Liski, M., 2018. Carbon prices for the next hundred years. Econ. J. 128, 728-757.

Glomm, G., Ravikumar, B., 1992. Public versus private investment in human capital: endogenous growth and income inequality. J. Polit. Econ. 100 (4), $818-834$.

Gollier, C., Tirole, J., 2015. Negotiating effective institutions against climate change. Econ. Energy Environ. Policy 4 (2), 5-28.

Golosov, M., Hassler, J., Krusell, P., Tsyvinski, A., 2014. Optimal taxes on fossil fuel in general equilibrium. Econometrica 82/1, 41-88.

Hettich, F., 1998. Growth effects of a revenue-neutral environmental tax reform. J. Econ. 67 (3), 287-316.

Jones, B.F., 2014. The human capital stock: a generalized approach. Am. Econ. Rev. 104, 3752-3777.

Lucas, R.E., 1988. On the mechanics of economic development. J. Monet. Econ. 22, 3-42.

Lucas, R.E., 2015. Reactions of new growth theory, human capital and growth.. Am. Econ. Rev. Pap. Proc. 105, 85-88.

Manuelli, R.E., Seshadri, A., 2014. Human capital and the wealth of nations. Am. Econ. Rev. 104, 2736-2762.

Michel, P., Rotillon, G., 1995. Disutility of pollution and endogenous growth. Environ. Resour. Econ. 6, $279-300$.

OECD, 2017. Boosting Skills for Greener Jobs in Flanders. Belgium, OECD Publishing, Paris. https://doi.org/10.1787/9789264265264-en.

Prices, H.-L. C. o. C., 2017. Report of the High-level Commission on Carbon Prices. Washington, DC: World Bank. 
Ricci, F., 2007. Channels of transmission of environmental policy to economic growth: a survey of the theory. Ecol. Econ. 60, 688-699.

Sapci, O., Shogren, J.F., 2018. Environmental quality, human capital and growth. J. Environ. Econ. Policy 7 (2), 184-203. doi:10.1080/21606544.2017.1384403.

Smulders, S., de Nooij, M., 2003. The impact of energy conservation on technology and economic growth. Resour. Energy Econ. 25/1, 59-79.

Stern, N., 2015. Why Are We Waiting? The Logic, Urgency, and Promise of Tackling Climate Change. The MIT Press, Cambridge, MA:

Strietska-Ilina, O., Hofmann, C., Haro, M.D., Jeon, S., 2012. Skills for Green Jobs: A Global View. International Labour Organisation., Geneva.

Vona, F., Marin, G., Consoli, D., Popp, D., 2018. Environmental regulation and green skills: An empirical exploration. J. Assoc. Environ. Resour. Econ. 5 (4), $713-753$

Weitzman, M., 2014. Can negotiating a uniform carbon price help to internalize the global warming externality? J. Assoc. Environ. Resour. Econ. 1 (1/2), 29-49.

Zivin, J.G., Hsiang, S.M., Neidell, M., 2016. Temperature and human capital in the short and long run. J. Assoc. Environ. Resour. Econ. 5/1, 77-105.

Zivin, J.G., Neidell, M., 2012. The impact of pollution on worker productivity. Am. Econ. Rev. 102/7, 3652-3673.

Zivin, J.G., Neidell, M., 2013. Environment, health, and human capital. J. Econ. Lit. 51/3, 689-730. 